\title{
Perceptions Of Nurse Educators About
}

Problem-based Learning

MF Khumalo

M.Cur

University of Orange Free State

Division of Student Learning

$\&$

NS Gwele

$\mathrm{PhD}$

University of Natal

Department of Nursing
"The nursing education system has

to aim at producing nurse professionals who are competent in the delivery of PHC to meet the changing needs of the South African society."

\section{Background}

The nursing education system has to aim at producing nurse professionals who are competent in the delivery of PHC to meet the changing needs of the South African society. This therefore, requires that nursing colleges in South Africa adopt curriculum approaches that develop links between theory and clinical practice and consequently prepare students to develop self directed learning skills, self reliance, the ability to utilise different intellectual, interpersonal and practical skills to make decisions and solve problems critically (SANC, 1985). A number of authors (Andrews \& Jones, 1996; Creedy \& Hand, 1994; Creedy, Horsfall \& Hand, 1992; Heliker, 1994) suggested Problem-based learning (PBL) as the most appropriate educational approach which will equip students with the skills necessary to function in a comprehensive and primary focused health delivery system.

Creedy and Hand (1994) maintained, however, that it was difficult to change educators' beliefs about their classroom practices because their pedagogical practices are based on their philosophical beliefs. Furthermore, Doring, Bramwell-Vial and Bingham (1995: 264) maintained that the individual's emotional response to change depends upon where the individual is at the process of change because "response is exacerbated by the individual's perceptions of change, their capacity to meet the change and the varying degrees they feel supported in the process." A change to $\mathrm{PBL}$ requires that nurse educators review their teaching practices and beliefs related to teaching and learning which will demand new skills and attitudes from them.

A study conducted by Bernstein, Tipping. Bercovitz and Skinner (1995) revealed that most tutors perceived $\mathrm{PBL}$ as more effective than the traditional method and as superior in terms of retention and reinforcement of information because according to the tutors, students in PBL sessions discussed issues with understanding rather than regurgitating memorised facts. These views were supported by Vernon (1995) who reported that educators were generally positive about $\mathrm{PBL}$ as compared to the traditional method because they perceived PBL as being of value to them and to the students by improving their interaction with the students, motivating students to learn, enhancing student-directed learning, problem solving skills, and creating a free and relaxed atmosphere in which to facilitate learning

The study by Doring, Bramwell-Vial and Bingham (1995) concluded that the extent of the educators' knowledge of PBL will influence the degree of their involvement in PBL, their teaching practices, and their preparedness for and comfort with the process. This was also confirmed by Vernon's findings (1995) which revealed that educators who had experience or previous knowledge regarding PBL were more positive towards it and were even willing to continue participating as tutors in it, than those with no or little knowledge of PBL.

A number of university nursing departments in South Africa have transformed their curricula to adopt PBL. Throughout the country, provincial health authorities are offering workshops for their staff to explore PBL as an alternative educational strategy in South African nursing colleges. Attempting an educational change of this magnitude poses an impressive challenge on nursing colleges in which the teacher-directed and content-based curriculum is still presently the most predominant approach used in nursing education. For nurse educators to adopt a change from the traditional teacher- centred approach to PBL, they must believe in student-centredness. An extensive literature search on the subject, however, yielded no South African studies dealing with the perceptions of 
nurse educators regarding PBL.

The investigators perceive PBL as a new approach in the South African nursing education institutions. Research of this nature can be of considerable value in identifying factors, specifically related to nurse educators, which can retard or promote the successful adoption and implementation of PBL. This study will make recommendations for nursing colleges in South Africa to take note of when seeking to implement PBL curricula through which the graduate will be equipped with the skills to cope with the changing primary health care needs of the society.

\section{The Purpose and Objectives of the Study \\ The purpose of this study was to deter-} mine and analyse the perceptions that nurse educators in South Africa hold regarding PBL and whether or not it would be feasible to implement this approach in the Nursing Colleges, as far as nurse educators are concerned. Hence, the objectives were to (a) examine the conceptualisations of PBL by nurse educators, (b) identify and analyse perceptions of nurse educators regarding PBL, and (c) investigate the perceived barriers and facilitating factors to implementing $\mathrm{PBL}$ in nursing colleges.

\section{Methodology}

This was a descriptive survey aimed at identifying the perceptions of nurse educators regarding $\mathrm{PBL}$ and its feasibility in nursing colleges. The target population of this study was all nurse educators teaching at selected nursing colleges in the Free State and KwaZulu Natal provinces. It was decided to use one big and one small college in each of the two provinces. In the Free State province, the big college (main nursing campus) had 37 nurse educators with 90 students intake per year. The small college (sub-campus) had 22 nurse educators in its establishment with 75 students intake per year. In KwaZulu Natal, the big nursing college had 48 nurse educators with 120 students intake per year, and the small nursing college had 10 nurse educators and 20 students intake per year.

Convenience sampling was done whereby two nursing colleges, one big and one small were selected from each of the mentioned provinces due to their geographical accessibility. The researcher submitted before hand an appointment time table to the heads of col- leges, to circulate amongst nurse educators for them to voluntarily indicate the times they availed themselves for interviews.

Twenty nine $(49 \%)$ of the total number of nurse educators (N'59) at both the small and big participating nursing colleges in the Free State Province and thirty $(52 \%)$ of the nurse educators ( $\left.N^{\prime} 58\right)$ at the participating nursing colleges in the KwaZulu Natal Province agreed to participate in the study. In all, therefore, $59(50 \%)$ of the 117 nurse educators targeted for participation in the study were interviewed.

\section{Instrumentation and Data Collection}

An interview schedule consisting of closed and open-ended questions was designed by the researchers. The closed ended questions were more on biographic data, teaching assignments and awareness about PBL. The openended questions sought information on perceptions and feelings about PBL as well as its feasibility in nursing colleges.

Consultation regarding the content validity of the instrument was confirmed by means of a discussion with research and educational experts (5). Experts supported the fact that the information sought on the perceptions of nurse educators regarding $\mathrm{PBL}$ through the interview schedule was relevant and therefore demonstrated content validity. The instrument was not tested for reliability because an interview schedule aimed at obtaining qualitative data is not amenable to traditional psychometric testing procedures.

A pilot study was conducted at a nonparticipating nursing college. Four nurse educators were interviewed. The first interview session took 11 minutes, the second: 25 minutes; the third: 18 minutes and the fourth: 15 minutes. The total was 79 minutes which amounted to an average of $\mathbf{2 0}$ minutes. Responses obtained from the pilot study assured the investigators that the interview schedule succeeded in eliciting information required to answer the questions raised in this study.

Structured individual interviews were used to collect data. Interviews were scheduled for 20 minutes each and appointments were arranged prior to visiting the nursing colleges. A copy of the interview appointment-time table was sent to each of the heads of the selected nursing colleges, with a letter attached asking those nurse educators who agreed to participate in the study to indicate by entering their names in the times that would suit them.

Each interview was recorded both on audio-tape and in writing. However, not all participants agreed to be interviewed on tape. Therefore, for these participants, only written records of the interviews were kept. The audio tapes were transcribed for analysis.

\section{Permission and Ethical \\ Considerations}

Permission for conducting the study was sought in a written form from health authorities of the provinces concerned and the heads of the participating nursing colleges. However, the participants were verbally asked to participate as mentioned before. No forms of identification of participants were asked. They were assured that information gathered was to be kept confidential, and would only be used for the purpose of the research.

\section{Limitations}

The researchers planned to interview all nurse educators in the selected nursing colleges. However, only 29 out of 59 nurse educators at the selected colleges in the Free state, and 30 out 58 in KwaZulu Natal agreed to participate. Nevertheless, the researchers regard this number as a very good response considering the fact that the research was conducted during a critical time when most nurse educators were not available because some were on study leave writing exams, others were busy marking students' examinations, others were conducting exams.

\section{Data Analysis}

Data obtained from the closed-ended questions were analysed by means of descriptive statistics. Qualitative data was analysed according to the categories derived from each question in the interview schedule. Themes, however, were derived from the interviewees' own responses. The unit of analysis for the open-ended questions' statements was the whole statement. That is, meaning was derived using the "whole" statements rather than sentences or words.

\section{Findings}

\section{Salient Sample Characteristics}

Of the 59 nurse educators, 45 were tu- 
tors, 11 were subject heads and 3 were vice principals. Most ( $n$ ' 27 ) of the participants had 2 - 6 years active teaching experience, followed by those who had seven or more years of teaching. Nine participants, however, had less than two years of teaching experience.

\section{Nurse Educators' Awareness Of PBL}

Ninety-five percent ( $n^{\prime} 56$ ) of the respondents reported that they were aware of PBL whereas $5 \%\left(n^{\prime} 3\right)$ said they were not aware of it. Seventy percent $(70 \%)$ of the respondents became aware of PBL from sources such as informal discussions with colleagues, and feed back reports from those who attended PBL workshops or conferences. Forty-one percent $(41 \%)$ of them read about PBL in literature, while $21 \%$ said that they attended PBL workshops or conferences and at least five of them said they attended a course that was problem-based.

\section{Conceptions Of PBL}

Five themes emerged from statements used by all nurse educators in explaining the meaning of PBL, namely: (a) approaches to teaching and learning, (b) the nature of the teaching-learning process, (c) an educational approach, (d) the process of PBL, and (e) the changing role of the teacher in PBL. The following excerpts from the respondents' own statements illustrate these observations

"PBL means that the student has to work through his/her own learning. Therefore, it involves: discovery learning, guided learning- where the teacher is a facilitator and programmed learning."

"I think it is a method that focuses on problems but it is more of a self-directed learning approach because the students are the ones who identify problems and solve them."

"PBL is process driven rather than content driven. It involves presenting students with a problem and allowing them to solve that problem themselves, using theoretical resources such as a library, practical resources such as patients in the wards. I will then act as a resource person, guiding them along the process."

"It means you send students out into the clinical setting with objectives. Whilst interacting with clients they identify problems. They can consult resources to get information related to the problems they have identified. The resources in this case would be books or people around the students. After researching on the problem, they come back to the tutor for clarity."

There seemed to be a confusion, however, between PBL and communitybased education (CBE). This was evidenced by the fact that some nurse educators viewed $\mathrm{PBL}$ as specifically related to community needs.

"PBL means that students are going to be placed in the community where they'll identify and solve problems. Their practical training will be based on the problems they identified in the community."

"To me it means the learning that is based on the needs of the consumer of health, which involves going out in the community, planning for the community needs and then executing that plan."

Seventy-one percent $(71 \%)$ of those nurse educators who defined PBL in terms of the role of the teacher viewed the teacher as a facilitator. In the contrary, the other $29 \%$ viewed the teacher as a provider of information.

\section{Perceptions Of Nurse Educators Regarding PBL} Fifty five $(95 \%)$ of the 59 nurse educators viewed PBL positively. Themes emerging from the statements made by those nurse educators who viewed PBL positively included: (a) the expected outcomes of PBL, such as retention of information, self-directed and active student leaning as well as student motivation (b) the changed role of the student, and (c) challenges facing the teacher. Some had the following to say:

"If the student identified the problem and discovered information for herself, then she will never forget that information."

I think PBL is the best approach because it allows the student to find out things for herself, to grow and to develop, and what is important, it develops the students' creative thinking, critical thinking and problem-solving skills.

"I think it is important because it helps the students to feel self-actualised especially if they have researched and discovered information on their own."

PBL is a good approach but it requires that the facilitator should be broad minded and well developed to be able to manage the students' viewpoints.

Some of the positive views expressed by the nurse educators could be seen as advantages of teaching with PBL. For instance some stated that:
"I wish we could adopt PBL because it would eliminate the problem of having to teach students everything which is in the syllabus, even irrelevant stuff, resulting in wastage of students' and tutors' time and unnecessary exhaustion of manpower (sic). "

"It enables students to see things (on site) practically, rather than theoretically. It is a realistic approach which has a long-term impact on the students' learning even after graduating."

A few nurse educators ( $n$ ' 4) saw mainly disadvantages in PBL. These were often related to time factors, and perceived inability of students to cope with PBL.

"I think that it is a good strategies except that it might be difficult for students who can't follow or understand easily."

"It is time consuming because it takes long for both the teacher and the student to review literature and research on problems identified."

Furthermore, a few were guarded in their optimism for implementing PBL in the nursing colleges. This was related to the timing of PBL implementation in a nursing education programme. They were not opposed to PBL provided it was implemented in the second year of the preregistration programme. In their view, first year students are still immature and therefore, need support of a teacher in learning. For instance one nurse educator stated:

"I like it but my concern is that first year students do not have enough knowledge and professional skills to work out problems in the community on their own. So I personally feel that it should be started from the second year level when students at least have an idea of what nursing entails."

\section{Factors That Would Facilitate Or Hinder The Implementation Of PBL}

Many facilitative factors of PBL implementation were mentioned by respondents and the most frequently mentioned were (a) in-service training of nurse educators and clinical staff regarding PBL, (b) positive change of attitudes towards PBL by the nurse educators, students and the college authorities, and (c) inclusion of PBL in nurse teacher educational programmes. The above observations are evident in the following statements:

"The most crucial factor that I can think of is the in-service training and education of nurse educators and the clinical 
sisters about PBL. By the way, don't forget that this is a new approach and we don't know much about it. My dear, if we do not know how to use it, then forget about its implementation. It is only if we understand what it entails, that maybe we can consider it. So I think that more workshops should be conducted to up date us ."

"It is important that nurse educators are updated about this approach. In actual fact, I think PBL should be implemented in the training of nurse educators so that they can get the skills and knowledge of its processes and be able to implement it better. I wish that the institutions which are presently offering $\mathrm{PBL}$ programmes could take more nurse educators, even if it is on a part-time basis."

"The most frequently mentioned hindering factors for the implementation of PBL in nursing colleges were (a) lack of information on PBL, (b) inadequate preparation of students for $\mathrm{PBL}$, and (c) negative attitudes towards PBL due to resistance to change."

"We will have problems with PBL because the type of students we get from high school never had a chance to discover information for themselves. They always expect the tutor to teach them everything, as a result they will not be able to cope with this method."

"Our negative attitude. It will take time for us to outgrow our traditional teaching because we are used to it. The nurse educators are reluctant to let go of the teaching and learning to the student because they feel they are experts and should therefore take sole control of the teaching and learning process."

"I question the present attitude of staff and students towards PBL. Are they ready to accept and implement it? I don't think so... I foresee a lot of resistance, especially from students because they were never introduced to this type of learning even at high school. They belong to the old school of thought of just coming to class and assimilating information. So we have to sell the idea of PBL before it is implemented."

Concern about lack and/or inadequacy of both human ( $\left.n^{\prime} 19\right)$ and material resources (n'28) was seen a major hindering factor by a number of nurse educators. These factors, coupled with large class sizes ( $\left.n^{\prime} 19\right)$ and a content-packed and examinations oriented curriculum (n '21) were seen by the participants in this study as some of major hindering factors to the implementation of PBL in nursing colleges

\section{Discussion}

The findings of this study revealed that the meaning of $\mathrm{PBL}$ is perceived differently by different persons. Some nurse educators defined PBL by describing its processes. Others defined it in terms of its distinctive features, such as student centred learning, self-directed learning, the process of learning. Others defined it in terms of its expected outcomes with reference to the knowledge and skills it develops in students such as creative thinking, critical thinking and self-directed learning (SDL) skills. Similarly, Albanese and Mitchell (1993), based on an extensive review of research on $\mathrm{PBL}$, conceded that it is difficult to arrive at a precise definition of the term.

The basic meaning of PBL by nurse educators, however, encompassed a teaching/learning process that involves problems which have to be solved by students through searching for information on their own, as self directed learners. Therefore, the meaning that the majority of nurse educators attached to PBL did not differ much from the meaning given by Barrows and Tamblyn (1980: 18) who defined PBL as "the learning that results from the process of working towards understanding or resolving a problem."

The knowledge that the nurse educators have about PBL seems to have influenced their views about it. For example, the majority of nurse educators who knew what PBL was viewed it positively, and those who said they did not know what it was, held noncommittal or negative views about it. Besides knowledge about PBL, other factors that could significantly have influenced the respondents views were more in terms of its benefits to the students, and their state of preparedness to utilise it as a teaching learning strategy. Similar findings were mentioned by Doring et. al (1995) and supported by Vernon (1995).

The participants were mostly positive about the effectiveness of PBL in areas of active student learning, academic and professional development of the students in terms of intellectual and problem solving skills. These findings are congruent with Norman and Schmidt (1992), Schmidt's (1983) views that PBL enhances the graduates' life-long learning skills. Similarly, emphasis on student centred learning and self directed learning was viewed by Barrows (1986) as the cornerstones of PBL.

The majority of nurse educators favoured PBL because they believed that it will motivate students to learn from selfdiscovery. In addition, the views of the respondents that PBL motivates students are supported by findings of the studies conducted by Vernon and Blake (1993), and Williams et al (1995). In South Africa, there is a need to produce autonomously and independently thinking nurses so that they are capable of rendering comprehensive health care (Gwele \& Uys, 1995). A reality of this objective can only be achieved if the educators foster an environment that is conducive for students to become motivated to direct their own learning. This however, has serious implications on the traditional role of the teacher because he or she has to let go of totalitarian control of the teaching/learning process. Nurse educators need to realise that the call for increased self-direction on the part of the students does imply either covertly or overtly, that nurse educators are abdicated from their responsibility to help students learn. Some of the respondents in the present study, however, saw the requirement for self-direction on the part of the students as a major barrier to implementation of PBL in South Africa.

PBL is generally regarded as an innovative approach and its adoption entails a whole range of processes of change which demands personal and professional reflection by educators (Creedy \& Hand, 1994). That being the case, it is interesting to note that the majority of nurse educators did not raise much concern about their perceived changed role in PBL but were more concerned about that of the students. Yet, according to Hord cited in Gwele and Uys (1995), it would have been natural for these educators to reflect on how they perceived PBL would affect their class room practices, in view of the fact that it is an innovative approach. However, the lack of concern for what a change from a content-driven to a problem-based curriculum would mean for them as nurse educators, might be attributable to the fact that none of the participating colleges were contemplating this change at the time of data collection. Hence there was no perceived immediate threat to their roles as nurse educators

The few nurse educators who did raise concerns about their changed role in $\mathrm{PBL}$, viewed $\mathrm{PBL}$ more as an approach that demanded their intellectual skills and competence. They mentioned that as facilitators, PBL requires them to be broad-minded and knowledgeable regarding the subject matter related to the problem, so that they are able to guide students appropriately. Similarly, Creedy et al (1992) supported the idea that the teachers facilitating PBL groups should have specialist in-depth knowledge of the subject so that they are able to track 
and explain the reasoning process undertaken. Within the context of this study however, the need to be knowledgeable about the subject matter was seen as extra burden on nurse educators.

A number of factors were identified by nurse educators as either facilitating or hindering the implementation of PBL in nursing colleges. Although generally nurse educators favoured PBL, the fact that they lacked information about it was of great concern. It was therefore not surprising that they perceived this as a major hindering factor of PBL implementation in nursing colleges. It is realised that this is a critical and legitimate concern, and nurse educators strongly felt that there is an essential need for them to be updated on PBL through workshops, in service training or short courses. The majority of literature pertaining to PBL, highlights the need for providing knowledge and skills to educators regarding PBL (Andrews \& Jones, 1996; Creedy et al, 1992; Doring et al, 1995). For example, Doring and colleagues asserted that for PBL programmes to be successfully implemented, educators must understand and be comfortable with the process, their roles and its outcome. Similarly, findings of the study conducted by Gwele (1996), confirmed that acceptance and ownership of a major curriculum change by educators is important for facilitating adoption and implementation.

Nurse educators in the study felt that knowledge about PBL is also required by college authorities and clinical staff, as people who are involved in the education of students in terms of the influence they have in the endorsement and adoption of the educational programmes. A similar view, but a different theme, was held by Gwele and Uys (1995), who maintained that all the people who are involved in the education of students, need to be involved at all levels of curriculum planning and decision making. This seems to be a very important factor in innovative processes.

\section{Conclusion}

The findings of this study have offered a description of some nurse educators' conceptions, perceptions and feelings about PBL. What is most important is that this study identified some factors which can facilitate or hinder the adoption and implementation of PBL in nursing colleges.

For PBL to be adopted at nursing colleges, an extensive amount of planning will first be required. Although nurse educators are aware and positive about PBL, there will be a need for them to be prepared by conducting a series of educational programmes such as workshops, seminars, forums, short courses, so that they know what PBL exactly entails in terms of the different forms of PBL available, the process of learning involved, the facilitation role of the teacher, the selfdirected role of the student, the objectives of PBL, the depth and breadth of knowledge in $\mathrm{PBL}$, the learning resources required, and the evaluation approaches used, and many other PBL related issues.

It is evident in the study, that nurse educators perceived PBL as a strategy that will mostly affect the student. Yet, in fact, it will require a lot of changes on their part before the students are affected because of the dominance of traditional teaching/learning practices in the nursing colleges. Besides, the findings of the study show that nurse educators were concerned about the ability of the students to learn on their own.

In view of the demands of the contentbased curricula used in most of the nursing colleges, the implementation of PBL will be impossible unless a restructuring of that curricula is effected to accommodate PBL.

Nurse educators felt that the students attitudes towards self-directed learning could be some of the hindering factors to implementing PBL at nursing colleges. A study aimed at examining the students views regarding PBL especially as it relates to self-directed learning, would be beneficial to nursing education in the country.

Forums consisting of students and staff from schools where PBL is implemented need to be established. Such forums would provide an arena for potential PBL adopters to ask questions of concern from them. That is, dissemination is of utmost importance for nurse educators in South Africa at this stage. 


\section{References}

Albanese, M. A., \& Mitchell, S. 1993. Problem-based learning: A review of literature on its outcome and implementation. Academic Medicine, 68 (1): 52-81.

Andrews, M., \& Jones, PR. 1996. Problem-based learning in an undergraduate nursing programme. Journal of Advanced Nursing, (23): 357-365.

Barrows, H. S. 1986. A taxonomy of problem-based learning methods. Medical Education, (20): 481-486.

Barrows, H. S., \& Tamblyn, R. M. 1980. Problem-based learning: An approach to medical education. New York: Springler Publishing Company.

Bernstein, P., Tipping, J., Bercovitz, K., \& Skinner, H. 1995. Shifting students and faculty to a PBL curriculum: Attitudes changed and lessons learned. Academic Medicine. 70 (3): 245-247.

Creedy, D., Horsfall, J., \& Hand, B. 1992. Problem-based learning in nurse education: an Australian view. Journal of Advanced Nursing, (17): 727-723.

Creedy, D. \& Hand, B. 1994. The implementation of problem-based learning: changing pedagogy in nursing education. Journal of Advanced Nursing, (20): 696-707.

Doring, A., Bramwell-Vial, A., \& Bingham, B. 1995. Staff comfort/discomfort with problem-based learning. A preliminary study. Nursing Education Today. (15): 265266

Gwele, N. S. 1996. Concerns of nurse educators regarding the implementation of a major curriculum reform. Journal of Advanced Nursing. (24): 607-614.

Gwele, N. S., \& Uys, L. R. 1995. Views of leading nurse educators regarding the comprehensive basic nursing programme. Curationis, 18 (1): 5-10.

Heliker, D. (1994). Meeting the challenge of the curriculum revolution: Problem-based learning in nursing education. Journal of Nursing Education, 33(1): 45-47.

Norman, G. R., \& Schmidt, H . G. (1992). The psychological basis of problem-based learning: a review of the evidence. Academic Medicine, 67(9): 557-565.

Schmidt, H. G. (1983). Problem-based learning: Rationale and description. Medical Education, (17): 11-16.

South African Nursing Council. 1985. R. 425. Regulations relating to approval and the for the education and training of a nurse (general, psychiatric and community) and midwife leading to registration. Pretoria: SANC. Feb.

Vernon, D. 1995. Attitudes and perceptions of faculty tutors about Problem-based Learning. Academic Medicine, 70 (3): 216-223.

Vernon, D. T. A., \& Blake, R. L. 1993. Does problem-based learning work?: a metaanalysis of evaluative research. Academic Medicine, (68): 550-562.

Williams, R., Saarinen-Rahikka., \& Norman, G. R. 1995. Self-directed learning in problem-based health science education. Academic Medicine, 70 (2):161-163. 